\title{
Primary care practitioner diagnostic action when the patient may have cancer: a vignette survey in 20 European countries
}

\author{
Michael Harris ( $\nabla$ mpsmfh@bath.ac.uk) \\ University of Bath https://orcid.org/0000-0002-7166-2971 \\ Mette Brekke \\ Universitetet i Oslo
}

Geert-Jan Dinant

Universiteit Maastricht

Magdalena Esteva

Balearic Islands Health Research Institute (IdISBa)

\section{Robert Hoffman}

Tel Aviv University

\section{Mercé Marzo-Castillejo \\ Institut Catala De La Salut \\ Peter Murchie}

University of Aberdeen

Ana Luísa Neves

Imperial College London

Emmanouil Smyrnakis

Aristotle University of Thessaloniki

\section{Peter Vedsted}

Aarhus Universitet

isabelle Aubin-Auger

Universite Paris Diderot

Joseph Azuri

Tel Aviv University

Krzysztof Buczkowski

Nicolaus Copernicus University

Nicola Buono

SNaMID

\section{Gergana Foreva}

Medical Center BROD

Svjetlana Gašparović Babić 
Croatian Health Insurance Fund

\section{Eva Jakob}

Centro de Saúde Sarria

\section{Tuomas Koskela}

Tampere University

\section{Davorina Petek}

University of Ljubljana

\section{Maria Petek Ster}

University of Ljubljana

\section{Aida Puia}

Universitatea de Medicina si Farmacie luliu Hatieganu

\section{Jolanta Sawicka-Powierza}

Uniwersytet w Bialymstoku

\section{Sven Streit}

Universitat Bern

\section{Hans Thulesius}

Lunds Universitet

Birgitta Weltermann

University of Bonn

\section{Gordon Taylor}

University of Exeter

\section{Research article}

Keywords: Delivery of Health Care; Primary Health Care; Cancer; Decision Making; Survival; Europe

Posted Date: August 15th, 2019

DOI: https://doi.org/10.21203/rs.2.12983/v1

License: (c) (i) This work is licensed under a Creative Commons Attribution 4.0 International License. Read Full License 


\section{Abstract}

Background Cancer survival rates vary widely between European countries, with differences in timeliness of diagnosis thought to be one key reason. There is little evidence on the way in which different healthcare systems influence Primary Care Practitioners' (PCPs') referral decisions in patients that could have cancer, and how this links with cancer survival. This study aimed to explore PCPs' diagnostic actions in patients with symptoms that could be due to cancer, how they vary across European countries with marked differences in socio-economic development, healthcare investment and organisation, and how they relate to cancer survival rates. Methods A primary care study, with centres in twenty European countries with widely varying cancer survival rates. The on-line survey of PCPs used vignettes describing four patients with symptoms that could indicate cancer (lung, ovary, breast and colorectal). PCPs were asked how they would manage these patients. Correlations between the likelihood of taking immediate diagnostic action and physician characteristics were calculated. The likelihood of taking immediate diagnostic action in the different participating countries was also analysed, as well as the correlation with national 1-year relative cancer survival rates. Results $A$ total of 2,086 PCPs answered the survey question, with a median of 72 PCPs per country. PCPs' likelihood of organising a diagnostic test and/or referring to a specialist at the first consultation varied from 50 to $82 \%$ between countries PCPs who were more experienced, were working in more remote areas, or worked alone or in smaller practices, were more likely to take immediate diagnostic action than their peers. There was a significant negative correlation between national healthcare expenditure levels and likelihood of immediate diagnostic action $(r=-0.55$, $P=0.012)$. However, there was no significant correlation between the likelihood of taking immediate diagnostic action and cancer survival $(r=-0.27, P=0.278)$. Conclusions Europe shows large betweencountry variations in PCPs' diagnostic action rates for patients who could have cancer. These are linked with differences in healthcare organisation and levels of healthcare investment.

\section{Background}

Cancer survival varies vary widely across Europe (1). The fifth cycle of the European Cancer Registry (EUROCARE)-based Study on Survival and Care of Cancer Patients shows that national 1-year relative survival rates for all cancer sites vary from $58.2 \%$ to $81.1 \%$ (2). Comparison of European 1-year relative cancer survival $(2-5)$ shows that some countries have higher survival from most cancers (including Belgium, France, Sweden and Switzerland), while others have consistently lower survival (including Bulgaria, Croatia, Poland and Scotland). This suggests that an improvement in cancer awareness and early detection in relatively poorly performing countries could reduce the survival gap (4). While recent cancer survival rates show improvement in most countries (5), the between-country differences remain (6). However, this is not inevitable: Denmark's considerable efforts to improve early detection rates (7) have resulted in a narrowing of the gap between its own relatively poor cancer survival rates and those of its better performing Nordic neighbours (8). There has been a call for studies which compare cancer diagnostic pathways between well and poorly performing countries, to help gain an understanding of how these disparities may be remedied (5). 
Although 1-year relative survival can be affected by differences in registration, as well as by overdiagnosis and lead-time biases $(9,10)$, poorer 1-year survival in some countries is thought to be rooted in diagnostic delay $(11,12)$ and more advanced disease at diagnosis $(13,14)$. The more advanced a cancer is, the more difficult it is to treat it successfully (15) and, for many cancers, disease stage at diagnosis is associated with survival $(16,17)$. There is considerable evidence that longer time to diagnosis and treatment increases cancer mortality (18-24). Timely diagnosis of cancer is, therefore, a cornerstone of health policy throughout Europe (25). However, there is a substantial challenge in deciding where and how to achieve this (26), as it is uncertain whether late diagnosis is due to cancer patients presenting later, not being referred quickly enough from primary care, or whether they are inefficiently investigated, diagnosed and treated in secondary care (15). This may be a particular issue where cancer patients present without 'red-flag' symptoms, as how the Primary Care Practitioner (PCP) acts will depend to a large extent on local health service organisation (27).

There is little evidence on how different healthcare systems influence PCPs' referral decisions (26). However, a large variety of non-clinical factors affect these referral decisions (27). These include the extent of gatekeeping, funding systems, access to special investigations, concerns over litigation, and barriers to accessing specialist advice. The International Cancer Benchmarking Partnership (ICBP) (28) examined differences in cancer awareness and beliefs between six countries with comparable wealth in an attempt to explain differences in cancer survival (29). It found a positive association between national cancer survival rates and the readiness of PCPs in those countries to investigate potential cancer symptoms (30). However, there has not yet been an investigation of how PCPs' diagnostic actions with respect to potential cancer symptoms vary across Europe, amongst countries with a wide range of socioeconomic development, healthcare systems and healthcare spending. We therefore aimed to explore the diagnostic action rates of PCPs for patients with symptoms that could be due to cancer, how they compare across European countries, and how they relate to cancer survival.

\section{Methods}

\section{Design}

We provided clinical vignettes to PCPs from twenty European countries with markedly different levels of socio-economic development, healthcare organisation and investment in healthcare. The vignettes described patients presenting with symptoms that could indicate cancer. Recruitment started in November 2015 and was completed at the end of 2016.

\section{Study population}

The Örenäs Research Group (ÖRG) is a European collaborative of primary care researchers, formed in 2013 to study the factors influencing national variations in the early diagnosis of cancer in primary care. The research was conducted in 25 ÖRG centres in 20 countries across Europe: Bulgaria, Croatia, Denmark, England, Finland, France, Germany, Greece, Israel, Italy, Netherlands, Norway, Poland, Portugal, 
Romania, Scotland, Slovenia, Spain, Sweden and Switzerland. Medical doctors were eligible for the survey if they were working mainly in primary care. These doctors, here referred to collectively as 'Primary Care Practitioners', included General Practitioners (GPs) and other doctors who had other specialist training but worked in the community and could be accessed directly by patients without referral.

\section{Development of the questionnaire}

Following a literature review, ÖRG investigators developed a questionnaire designed to elicit PCPs' diagnostic actions for patients that could have cancer. A questionnaire with five clinical vignettes was piloted by the ÖRG local leads in January 2015 to check validity. One of the vignettes was found to be invalid and was removed. The next version of the questionnaire, in English, was then piloted by 49 PCPs in 16 ÖRG member countries in July 2015. No changes to the vignettes were made following this second pilot.

ÖRG leads arranged for translations of the questionnaire into their local languages where these were not English, a total of 19 translations from the original English. Translation and validation by backtranslation were done in a standardised way (31) and are described elsewhere (32).

\section{Description of the questionnaire}

The questionnaire consisted of 47 items and was divided into four sections: (a) demographic questions (five questions about years since graduation, gender, type and rural/urban location of practice and number of doctors working in the practice); (b) referral availability questions (two questions about tests and specialist opinions that were either directly or indirectly available to the respondent); (c) four clinical vignettes and (d) 20 health system factor questions. Each of the vignettes provided information on the patient's presenting symptoms, previous medical history, medication, clinical findings and other relevant information. Two of the vignettes were designed and validated by the ICBP (33), and used with permission. The vignettes were:

1. A 62-year-old male smoker with chronic obstructive pulmonary disease and now a two-week history of a productive cough; positive predictive value (PPV) for lung cancer: $3.6 \%$ (34);

2. A 53-year-old woman with lower abdominal pain and abdominal distension; PPV for ovarian cancer: $3.1 \%$ (35);

3. A 35-year-old breastfeeding woman with an abnormal nipple discharge and eczematous changes around the nipple; PPV for breast cancer: $1.2 \%$ (36);

4. A 22-year-old man with coeliac disease who now has abdominal pain, rectal bleeding and diarrhoea; PPV for colorectal cancer: $3.4 \%$ (34).

For each patient, a range of five possible management decisions was given (whether the respondent would prescribe medication, arrange a follow-up appointment, use watchful waiting, organise a 
diagnostic test, refer the patient), with a 'yes/no' option for each. Those that chose to investigate the patient were able to select from a range of possible diagnostic tests. The response of primary interest was a PCPs' management choice that would be likely to identify a cancer as a cause of the patients' symptoms, by either opting to request a significant diagnostic test or by referring to a specialist. The tests used in the analysis were: a plain chest X-ray or lung computerised tomography (CT) for the lung vignette; a tumour marker, diagnostic ultrasound or CT for the ovarian vignette; an ultrasound of the breast or mammography for the breast vignette; and diagnostic ultrasound, sigmoidoscopy, colonoscopy or CT colonography for the colorectal vignette. A factor analysis of the results of the survey section on the effect of health system factors is reported separately (37).

\section{Sample size}

We aimed for a total sample size of at least 1000 PCPs, with at least 50 responses from each of the participating countries.

\section{Recruitment of participants}

Each ÖRG local lead was asked to email an invitation to take part in the survey to the PCPs in their local health district or jurisdiction, and to recruit at least 50 participants. In six countries (Denmark, Norway, Portugal, Romania, Slovenia, Sweden), the invitation was distributed to a national sample. The recruitment email stated that the research aimed to identify which health system factors affect PCPs' decisions to refer patients for further investigation. The possibility of cancer as being a cause of the vignette symptoms was not mentioned in either the recruitment email or the survey. As low survey response rates are common in primary care (38) and can vary between jurisdictions, any local leads who had difficulty in achieving the required sample sizes were asked to increase the number of responses by using snowballing, a recognised technique for recruiting hard-to-reach populations in health studies $(39,40)$.

\section{Distribution of the questionnaire}

The questionnaire was designed using SurveyMonkey (41). Because of the study's wide geographical coverage, on-line delivery of the questionnaire was used; this methodology has previously been successfully used in research involving cancer care professionals (42).

\section{Statistical analysis}

Demographic questions and those relating to vignette diagnostic actions were analysed using descriptive statistics for decision to arrange a diagnostic test, and to refer to a specialist. As it was considered that some PCPs would not investigate because they were referring to a specialist, and conversely some PCPs 
would not refer to a specialist because they were investigating, we also used a composite measure of a decision to either arrange a diagnostic test and/or refer to a specialist, i.e. the likelihood of taking diagnostic action for cancer. For each individual PCP, mean diagnostic action rates were calculated from the four individual vignette responses. From those, mean diagnostic action rates were calculated for each country. For comparisons between countries, medians and ranges were calculated.

For each country, the mean 1-year and 5-year relative cancer survival rates for the four cancers of interest (lung, ovary, breast and colorectal) were calculated from EUROCARE-5 data (2). These are shown in Table 1. Linear correlations and 2-tailed significance levels were estimated for the proportions of PCPs opting to take diagnostic action and these national 1-year relative cancer survival rates, and also between PCPs' likelihood of organising a diagnostic test and their likelihood of referral to a specialist. As one-year relative survival rates for cancer can be affected by lead-time bias, we made a sensitivity analysis using 5-year survival.

\section{Results}

A total of 2,086 PCPs completed the questionnaire. There was a median of 72 respondents per country, range 59-446 (Table 1).

The median response rate per country was $24.8 \%$ (range $7.1 \%$ to $65.6 \%$ ). Participants' demographic distributions are shown in Table 2.

\section{Organising a diagnostic test}

The range of PCPs who stated that they would organise a diagnostic test at this first consultation varied from $35.6 \%-80.1 \%$, median $53.0 \%$ (Figure 1 ).

\section{Referring the patient to a specialist}

Across the participating countries, a median of 34.2 , range $12.3 \%-64.7 \%$, of PCPs decided to refer the patient to a specialist at the first consultation (Figure 2).

\section{Arranging a diagnostic test and/or referring the patient to a specialist}

There was a strong correlation between PCPs' likelihood of arranging a diagnostic test and their likelihood of referral to a specialist: $r=0.77, P=<0.001$. Across the surveyed countries, the proportion of PCPs who would take diagnostic action at this first consultation (i.e. organise a diagnostic test and/or refer) varied from $50.0 \%$ to $82.1 \%$, median $59.9 \%$ (Figure 3 ). 


\section{Correlation between decision to take diagnostic action and national cancer survival rates}

Overall, there was no significant correlation between likelihood of immediate diagnostic testing and/or referral rates and 1-year relative cancer survival rates $(r=-0.27, P=0.278)$ (Figure 4). In the sensitivity analysis based on 5 -year relative cancer survival rates, the values were similar $(r=-0.28, P=0.267)$. The degree of correlation with 1-year relative cancer survival varied between the vignettes: lung cancer vignette, $r=-0.016, P=0.951$; ovarian cancer vignette, $r=-0.31, P=0.205$; breast cancer vignette, $r=-$ $0.43, P=0.076$; colorectal cancer vignette, $r=-0.36, P=0.146$.

\section{Correlation of diagnostic action with PCP demographics}

There was no significant gender difference for taking immediate diagnostic action: for female PCPs, the likelihood was $62.7 \%$, for male GPs it was $61.3 \%, P=0.346$. There was, however, a link between the number of years since graduation and the likelihood of taking immediate diagnostic action (Table 3): a mean of $55.5 \%$ of PCPs who had graduated less than 10 years ago were likely to take diagnostic action, compared with a mean of $63.4 \%$ for those who had graduated 10 or more years ago, $P<0.001$.

In the twelve countries with respondents who self-identified as working in remote or island practices, those PCPs were significantly more likely to take immediate diagnostic action than their colleagues (71.4\% vs. $60.7 \%, P=0.021$ ). There was a trend towards lower likelihood of investigation and/or referral with larger practices, Table 4.

\section{Correlation of diagnostic action with national healthcare expenditures}

National healthcare expenditures, measured as Purchasing Power Parity (PPP) Current International Dollars per capita (43), are given in Table 1. There was a significant negative correlation between national per capita healthcare expenditure and PCPs' likelihood of taking immediate diagnostic action $(r=-0.55$, $P=0.012)$, Figure 5.

\section{Discussion}

\section{Principal findings}

When faced with vignettes of patients with symptoms that could be due to cancer, there was a marked variation between different European countries in PCPs' stated actions. In all the participating countries at least half of PCPs would have taken an immediate diagnostic action (i.e. either organised a diagnostic test or referred the patients to a specialist, or both). There was a significant negative correlation between national healthcare expenditure levels and likelihood of PCPs' immediate diagnostic action, but no 
significant correlation between the likelihood of taking diagnostic action and cancer survival. PCPs who were more likely to arrange a diagnostic test were also more likely to refer their patients to a specialist at the same time.

PCPs who had graduated more recently were less likely to take diagnostic action than their more experienced peers, but PCPs working in more remote locations were more likely to take diagnostic action than their colleagues in other localities. PCPs working alone or in smaller practices were more likely to take diagnostic action than those in larger practices.

\section{Strengths and limitations of the study}

One of the strengths of our study is the wide spectrum of participating centres, with four countries from each of the Central, Eastern, Northern, Southern and Western European geographical areas, providing variation in geography, socioeconomic and health systems, and levels of healthcare spending. It included the views of PCPs who are not usually involved in research. The questionnaire was carefully developed and piloted by GPs and other PCPs, and therefore grounded in their clinical experience. While low survey response rates are common in primary care (38) and are known to vary between countries, those in our study compared favourably with those of a recent ICBP survey, in which response rates varied from $5.5 \%$ to $45.6 \%$ (30). There is evidence that responses to vignettes in surveys correspond well to clinical practice (44), and such surveys have previously been used to study primary care investigation preferences in patients who could have cancer $(30,45)$.

Our study examined groups of PCPs as the unit of observation. Measuring the possible link between these groups' stated actions and national cancer survival creates the risk of an ecological fallacy (46), as any identified correlation may be an indicator of the effect of unmeasured system factors. While the demographic data that we collected included the gender of participants and the number of years that they had been in practice, we have found no equivalent data on national PCP populations that would allow us to assess how representative our samples were.

Most samples were taken from each local lead's own locality, and these may not have been representative of their nations as a whole (47). The recruitment method used in this study resulted in variable response rates, leading to a risk of non-response bias (38). However, the goal of 50 survey participants per country and more than 1000 respondents in total was achieved. We have no data on nonresponders as the survey was anonymous, however this anonymity might have reduced the risk of social desirability bias. It is possible that the PCPs with the most interest in diagnostic decision-making were the most likely to respond.

\section{Interpretation of the results}

Diagnostic testing and referral rates differed widely between participating countries. Whereas we might expect that referring a patient would result in the PCP being less likely to investigate the patient her- or 
himself, and vice versa, this was not confirmed in the survey: the more likely PCPs were to refer a patient, the more likely they were to organise a diagnostic test at the same time.

While we found that PCPs working in remote locations were more likely to take diagnostic action, this may be due to confounding, as doctors with young families have been found to be less likely to work rurally (48), and we found that more experienced PCPs were more likely to take diagnostic action.

\section{Comparison with existing literature}

In contrast to our study, an ICBP study showed a positive correlation between jurisdictional cancer survival rates and readiness to investigate or refer to secondary care in 4 out of 5 of its vignettes (30). However, it only studied five, relatively wealthy, countries (Australia, Canada, Denmark, Norway, Sweden and the United Kingdom). While the ICBP research found no health system characteristics that explained their findings, our study shows a link between PCP diagnostic actions and practice location, size of practice and PCP experience. Our finding of a lower likelihood of diagnostic action for PCPs working in larger practices corresponds with other study findings (49). Our evidence that PCPs working in more remote locations were more likely to take diagnostic action links across to evidence that such remote living is associated with more rapid cancer diagnosis and treatment following GP referral (50). While our data show higher diagnostic action rates in PCPs with more years since graduation, the opposite was found in a Finnish study (51), and no difference was found in a United Kingdom study (52). However, those two studies did not specifically study referrals for suspected cancer: it may be that experienced PCPs are more likely to recognise symptoms that suggest a possibility of cancer, even in the absence of 'red-flag' symptoms.

The extent to which respondents were gatekeepers, and needed to authorise their patients' access to specialist care and diagnostic tests (53), may have been a factor in their diagnostic actions. There has been a suggestion that stronger gatekeeper systems are linked with lower 1-year relative cancer survival than non-gatekeeper systems (54), possibly because gatekeeping can result in cost and resource decisions which reduce the likelihood of early referral (55). However, there are important variations in the level of gatekeeping between countries, with no simple binary model as to whether or not a country has a 'GP-as-gate-keeper' system, and a European study found no association between cancer survival and a probability of presentation to a GP (56).

\section{Implications for research and practice}

The poorer survival in some of our surveyed countries appears not to be due to delayed referral from primary care, suggesting that the cause may be related to cancer patients presenting later, or being less efficiently investigated, diagnosed and treated in secondary care. It may be that in those countries a stronger gate-keeper role for primary care, allowing secondary care to focus on patients that have a higher risk of cancer, would be more effective. 
While it might be expected that PCPs who are more likely to arranging a diagnostic test would be less likely to refer their patient in the same consultation, we found the opposite was the case, and research is needed to explain this. We cannot explain our finding that PCPs in countries with a higher per capita healthcare expenditure were less likely to take immediate diagnostic action, and the reasons for this need investigation.

\section{Conclusions}

When given vignettes of patients with a low but significant possibility of cancer, more than half of PCPs across Europe would take diagnostic action, most often by ordering diagnostic tests. However, there are substantial between-country differences, which are linked with the healthcare organisation in those countries, as well as their levels of investment in healthcare. In countries with higher healthcare expenditure, immediate diagnostic action is less likely.

\section{List Of Abbreviations}

CT Computerised Tomography

GNP Gross National Product

GP General practitioner

ICBP International Cancer Benchmarking Partnership

ÖRG Örenäs Research Group

PCP Primary Care Physician

PPP Purchasing Power Parity

PPV Positive Predictive Value

\section{Declarations}

\section{Ethics approval and consent to participate}

Ethical approval for the study was given by the University of Bath Research Ethics Approval Committee for Health (approval date: 24th November 2014; REACH reference number: EP 14/15 66). Other countries' study leads either achieved local ethical approval or gave statements that formal ethical approval was not needed in their jurisdictions (see supplementary file).

Potential participants were sent a Participant Information Sheet, and consent was implied by agreeing to take part in the survey. 


\section{Consent for publication}

Not applicable.

\section{Availability of data and material}

To avoid the risk of identification of individual participants, the datasets generated and analysed during the current study are not publicly available. However, they are available from the corresponding author on reasonable request.

\section{Competing interests}

The authors declare that they have no competing interests.

\section{Funding}

This study received no specific grant from any funding agency in the public, commercial or not-for-profit sectors. ALN is supported by the National Institute for Health Research (NIHR) Imperial Patient Safety Translation Research Centre, with infrastructure support provided by the NIHR Imperial Biomedical Research Centre (BRC).

\section{Authors' contributions}

IA-A, JA, KB, MB, NB, G-JD, ME, GF, SGB, MH, RH, EJ, TK, MM-C, PM, ALN, AP, DP, MPS, JS-P, ES, SS, GT, HT, $\mathrm{PV}$ and BW participated in the study design. All authors except GT were involved in the data collection. All authors contributed to the manuscript and approved the final version. MH had overall responsibility for the study design, recruitment of local leads, analysis of data and interpretation of results. GT advised on the study design and the statistical analysis.

\section{Acknowledgements}

We would like to thank all the PCPs who piloted the questionnaire and those who completed the survey. We would also like to thank the European GP Research Network for its support. We are grateful to Prof. Barbara Silverman and Prof. Lital Keinan for the data on cancer survival rates in Israel, and to Dr Yochai Schonmann for his work on those data. Two of the vignettes were used by kind permission of the ICBP; we also thank Dr Peter Murchie and Dr Rhona Auckland, who generously provided the other two vignettes. Prof. Antonius Schneider kindly organised the Technical University of Munich's data collection.

\section{References}


1. Møller $\mathrm{H}$, Linklater KM, Robinson D. A visual summary of the EUROCARE-4 results: a UK perspective. Br J Cancer. 2009;101(Suppl 2):S110-4.

2. EUROCARE. EUROCARE-5. Istituto Nazionale Tumori (Milan) and Istituto Superiore di Sanità (Rome); 2014. (Eurocare. Survival of cancer patients in Europe.).

3. EUROCARE. EUROCARE-4. Istituto Nazionale Tumori (Milan) and Istituto Superiore di Sanità (Rome); 2011. (Eurocare. Survival of cancer patients in Europe.).

4. Thomson CS, Forman D. Cancer survival in England and the influence of early diagnosis: what can we learn from recent EUROCARE results? Br J Cancer. 2009;101 Suppl 2:S102-S109.

5. De Angelis R, Sant M, Coleman MP, Francisci S, Baili P, Pierannunzio D, et al. Cancer survival in Europe 1999-2007 by country and age: results of EUROCARE- 5 - a population-based study. Lancet Oncol. 2014;15(1):23-34.

6. Coleman MP, Forman D, Bryant H, Butler J, Rachet B, Maringe C, et al. Cancer survival in Australia, Canada, Denmark, Norway, Sweden, and the UK, 1995-2007 (the International Cancer Benchmarking Partnership): an analysis of population-based cancer registry data. Lancet. 2011;377(9760):127-38.

7. Storm HH, Gislum M, Engholm G. [Cancer survival before and after initiating the Danish Cancer Control plan]. Ugeskr Laeger. 2008 Sep 22;170(39):3065-9.

8. Allemani C, Matsuda T, Carlo VD, Harewood R, Matz M, Nikšić M, et al. Global surveillance of trends in cancer survival 2000-14 (CONCORD-3): analysis of individual records for 37513025 patients diagnosed with one of 18 cancers from 322 population-based registries in 71 countries. Lancet. 2018 Mar 17;391(10125):1023-75.

9. Zahl PH, Jorgensen KJ, Gotzsche PC. Overestimated lead times in cancer screening has led to substantial underestimation of overdiagnosis. Br J Cancer. 2013 Oct 1;109(7):2014-9. doi: 10.1038/bjc.2013.427. Epub 2013 Aug 20.

10. Carter JL, Coletti RJ, Harris RP. Quantifying and monitoring overdiagnosis in cancer screening: a systematic review of methods. BMJ. 2015 Jan 7;350:g7773.(doi):10.1136/bmj.g7773.

11. Maringe C, Walters S, Rachet B, Butler J, Fields T, Finan P, et al. Stage at diagnosis and colorectal cancer survival in six high-income countries: a population-based study of patients diagnosed during 2000-2007. Acta Oncol. 2013 Jun;52(5):919-32. doi: 10.3109/0284186X.2013.764008. Epub 2013 Apr 15.

12. Walters S, Maringe C, Coleman MP, Peake MD, Butler J, Young N, et al. Lung cancer survival and stage at diagnosis in Australia, Canada, Denmark, Norway, Sweden and the UK: a population-based study, 2004-2007. Thorax. 2013 Jun;68(6):551-64.

13. Richards MA. The size of the prize for earlier diagnosis of cancer in England. Br J Cancer. 2009;101 Suppl 2:S125-S129.

14. Woods LM, Coleman MP, Lawrence G, Rashbass J, Berrino F, Rachet B. Evidence against the proposition that 'UK cancer survival statistics are misleading': simulation study with National Cancer Registry data. BMJ. 2011 Jun 9;342:d3399.(doi):10.1136/bmj.d3399. 
15. Butler J, Foot C, Bomb M, Hiom S, Coleman M, Bryant H, et al. The International Cancer Benchmarking Partnership: An international collaboration to inform cancer policy in Australia, Canada, Denmark, Norway, Sweden and the United Kingdom. Health Policy. 2013 Sep 1;112(1):14855.

16. Green $\mathrm{T}$, Atkin $\mathrm{K}$, Macleod U. Cancer detection in primary care: insights from general practitioners. $\mathrm{Br}$ J Cancer. 2015 03/online;112:S41.

17. Jacobsen MM, Silverstein SC, Quinn M, Waterston LB, Thomas CA, Benneyan JC, et al. Timeliness of access to lung cancer diagnosis and treatment: A scoping literature review. Lung Cancer. 2017 Oct;112:156-64.

18. McLaughlin JM, Anderson RT, Ferketich AK, Seiber EE, Balkrishnan R, Paskett ED. Effect on survival of longer intervals between confirmed diagnosis and treatment initiation among low-income women with breast cancer. J Clin Oncol. 2012 Dec 20;30(36):4493-500.

19. Yun YH, Kim YA, Min YH, Park S, Won YJ, Kim DY, et al. The influence of hospital volume and surgical treatment delay on long-term survival after cancer surgery. Ann Oncol. 2012 Oct;23(10):2731-7.

20. Gobbi PG, Bergonzi M, Comelli M, Villano L, Pozzoli D, Vanoli A, et al. The prognostic role of time to diagnosis and presenting symptoms in patients with pancreatic cancer. Cancer Epidemiol. 2013 Apr;37(2):186-90.

21. Tørring ML, Frydenberg M, Hansen RP, Olesen F, Vedsted P. Evidence of increasing mortality with longer diagnostic intervals for five common cancers: a cohort study in primary care. Eur $\mathrm{J}$ Cancer. 2013 Jun;49(9):2187-98.

22. Elit LM, O'Leary EM, Pond GR, Seow HY. Impact of wait times on survival for women with uterine cancer. J Clin Oncol. 2014 Jan 1;32(1):27-33.

23. Nanthamongkolkul K, Hanprasertpong J. Longer waiting times for early stage cervical cancer patients undergoing radical hysterectomy are associated with diminished long-term overall survival. J Gynecol Oncol. 2015 Oct;26(4):262-9.

24. Neal RD, Tharmanathan P, France B, Din NU, Cotton S, Fallon-Ferguson J, et al. Is increased time to diagnosis and treatment in symptomatic cancer associated with poorer outcomes? Systematic review. Br J Cancer. 2015 Mar 31;112 Suppl 1:S92-107.

25. Malmström M, Rasmussen BH, Bernhardson B-M, Hajdarevic S, Eriksson LE, Andersen RS, et al. 'It is important that the process goes quickly, isn't it?' A qualitative multi-country study of colorectal or lung cancer patients' narratives of the timeliness of diagnosis and quality of care. Eur $\mathrm{J}$ Oncol Nurs. 2018;34:82-8.

26. Foot C, Harrison T. How to improve cancer survival: explaining England's relatively poor rates. The King's Fund; 2011.

27. Harris M, Frey P, Esteva M, Gašparović-Babić S, Marzo-Castillejo M, Petek D, et al. How health system factors influence referral decisions in patients that may have cancer: European symposium report. J Cancer Res Ther. 2016;4(1):7-10.

28. International Cancer Benchmarking Partnership. ICBP Newsletter. Cancer Research UK; 2011. 
29. Forbes LJL, Simon AE, Warburton F, Boniface D, Brain KE, Dessaix A, et al. Differences in cancer awareness and beliefs between Australia, Canada, Denmark, Norway, Sweden and the UK (the International Cancer Benchmarking Partnership): do they contribute to differences in cancer survival? Br J Cancer. 2013;108(2):292-300.

30. Rose PW, Rubin G, Perera-Salazar R, Almberg SS, Barisic A, Dawes M, et al. Explaining variation in cancer survival between 11 jurisdictions in the International Cancer Benchmarking Partnership: a primary care vignette survey. BMJ Open. 2015 May 27;5(5):e007212. doi: 10.1136/bmjopen-2014007212.

31. Brett J, Staniszewska S, Mockford C, Herron-Marx S, Hughes J, Tysall C, et al. Mapping the impact of patient and public involvement on health and social care research: a systematic review. Health Expect. 2014 Oct; 17(5):637-50.

32. Harris M, Taylor G, Örenäs Research Group. How health system factors affect primary care practitioners' decisions to refer patients for further investigation: protocol for a pan-European ecological study. BMC Health Serv Res. 2018 May 8;18(1):338.

33. Rose PW, Hamilton W, Aldersey K, Barisic A, Dawes M, Foot C, et al. Development of a survey instrument to investigate the primary care factors related to differences in cancer diagnosis between international jurisdictions. BMC Fam Pr. 2014 Jun 17;15:122.(doi):10.1186/1471-2296-15-122.

34. Hamilton W. The CAPER studies: five case-control studies aimed at identifying and quantifying the risk of cancer in symptomatic primary care patients. Br J Cancer. 2009 Dec 3;101 Suppl 2:S80-6.

35. Hamilton W, Peters TJ, Bankhead C, Sharp D. Risk of ovarian cancer in women with symptoms in primary care: population based case-control study. BMJ. 2009;339:b2998.

36. Walker S, Hyde C, Hamilton W. Risk of breast cancer in symptomatic women in primary care: a casecontrol study using electronic records. Br J Gen Pract. 2014 Dec;64(629):e788-93.

37. Harris M, Vedsted P, Esteva M, Murchie P, Aubin-Auger I, Azuri J, et al. Identifying important health system factors that influence primary care practitioners' referrals for cancer suspicion: a European cross-sectional survey. BMJ Open. 2018;8(9).

38. Pit SW, Vo T, Pyakurel S. The effectiveness of recruitment strategies on general practitioner's survey response rates - a systematic review. BMC Med Res Methodol. 2014;14:76.

39. Shaghaghi A, Bhopal RS, Sheikh A. Approaches to Recruiting 'Hard-To-Reach' Populations into Research: A Review of the Literature. Health Promot Perspect. 2011;1(2):86-94.

40. Atkinson R, Flint J. Accessing Hidden and Hard-to-Reach Populations: Snowball Research Strategies. Guildford, UK; 2001.

41. SurveyMonkey [Internet]. [cited 2019 Apr 30]. Available from: https://www.surveymonkey.net/

42. Dobrow MJ, Orchard MC, Golden B, Holowaty E, Paszat L, Brown AD, et al. Response audit of an Internet survey of health care providers and administrators: implications for determination of response rates. J Med Internet Res. 2008;10(4):e30.

43. The World Bank. Current health expenditure per capita, PPP (current international \$) [Internet]. 2018. Available from: https://data.worldbank.org/indicator/SH.XPD.CHEX.PP.CD 
44. Peabody JW, Luck J, Glassman P, Jain S, Hansen J, Spell M, et al. Measuring the quality of physician practice by using clinical vignettes: a prospective validation study. Ann Intern Med. 2004 Nov 16;141(10):771-80.

45. Banks J, Hollinghurst S, Bigwood L, Peters TJ, Walter FM, Hamilton W. Preferences for cancer investigation: a vignette-based study of primary-care attendees. Lancet Oncol. 2014;15(2):232-40.

46. Freedman D. Ecological Inference and the Ecological Fallacy. California, USA.; 1999.

47. Greenacre Z. The Importance of Selection Bias in Internet Surveys. Open J Stat. 2016;6:397-404.

48. McGrail MR, Russell DJ, O'Sullivan BG. Family effects on the rurality of GP's work location: a longitudinal panel study. Hum Resour Health [Internet]. 2017 Oct 19 [cited 2019 May 2];15. Available from: https://www.ncbi.nlm.nih.gov/pmc/articles/PMC5649059/

49. Verstappen WH, ter Riet G, Dubois WI, Winkens R, Grol RP, van der Weijden T. Variation in test ordering behaviour of GPs: professional or context-related factors? Fam Pract. 2004 Aug 1;21(4):387-95.

50. Turner M, Fielding S, Ong Y, Dibben C, Feng Z, Brewster DH, et al. A cancer geography paradox? Poorer cancer outcomes with longer travelling times to healthcare facilities despite prompter diagnosis and treatment: a data-linkage study. Br J Cancer. 2017 Jul 25;117(3):439-49.

51. Vehvilainen AT, Kumpusalo EA, Voutilainen SO, Takala JK. Does the doctors' professional experience reduce referral rates? Evidence from the Finnish referral study. Scand J Prim Health Care. 1996 Mar;14(1):13-20.

52. Wilkin D, Smith AG. Variation in general practitioners' referral rates to consultants. J R Coll Gen Pr. 1987 Aug;37(301):350-3.

53. Franks P, Clancy CM, Nutting PA. Gatekeeping revisited-protecting patients from overtreatment. N Engl J Med. 1992 Aug 6;327(6):424-9.

54. Vedsted $P$, Olesen $F$. Are the serious problems in cancer survival partly rooted in gatekeeper principles? Br J Gen Pr. 2011;61(589):512-3.

55. Neal RD. Commentary. Cancer diagnosis - the role of urgent referral guidelines. Br J Gen Pract J R Coll Gen Pract. 2010 Feb;60(571):127.

56. Harris M, Frey P, Esteva M, Gašparović Babić S, Marzo-Castillejo M, Petek D, et al. How the probability of presentation to a primary care clinician correlates with cancer survival rates: a European survey using vignettes. Scand J Prim Health Care. 2017;27-34.

\section{Tables}

Table 1. Number of respondents per country, response rates, mean national cancer survival rates for the four cancers of interest, and healthcare expenditures (given as PPP Current International Dollars per capita). 


\begin{tabular}{|c|c|c|c|c|c|c|c|}
\hline & & $\begin{array}{c}\text { Number of } \\
\text { respondents (\% } \\
\text { of all } \\
\text { respondents) }\end{array}$ & $\begin{array}{l}\text { Number } \\
\text { of PCPs } \\
\text { invited }\end{array}$ & $\begin{array}{l}\text { Response } \\
\text { rate (\%) }\end{array}$ & $\begin{array}{c}\text { 1-year } \\
\text { relative } \\
\text { cancer } \\
\text { survival } \\
\text { (\%) }\end{array}$ & $\begin{array}{c}\text { 5-year } \\
\text { relative } \\
\text { cancer } \\
\text { survival } \\
\text { (\%) }\end{array}$ & $\begin{array}{l}\text { Healthcare } \\
\text { expenditure } \\
\text { per capita, } \\
\text { PPP\$ }\end{array}$ \\
\hline \multirow{21}{*}{$\begin{array}{l}\text { Respondents per } \\
\text { country (in } \\
\text { alphabetical } \\
\text { order) }\end{array}$} & Bulgaria & $59(2.8)$ & 90 & 65.5 & 59.6 & 38.4 & 1399 \\
\hline & Croatia & $67(3.2)$ & 292 & 22.9 & 63.7 & 44.7 & 1652 \\
\hline & Denmark & $107(5.1)$ & 400 & 26.8 & 69.0 & 45.4 & 4782 \\
\hline & England & $65(3.1)$ & 300 & 21.7 & 65.2 & 42.7 & 3377 \\
\hline & Finland & $65(3.1)$ & 178 & 36.5 & 73.2 & 50.3 & 3701 \\
\hline & France & $59(2.8)$ & 550 & 10.7 & 74.9 & 49.8 & 4508 \\
\hline & Germany & $103(4.9)$ & 242 & 42.6 & 73.5 & 50.3 & 5182 \\
\hline & Greece & 68 (3.3) & 318 & 21.4 & \multicolumn{2}{|c|}{ Data not available } & 2098 \\
\hline & Israel & $75(3.6)$ & 339 & 22.1 & $79.2^{*}$ & $58.3^{*}$ & 2599 \\
\hline & Italy & $63(3.0)$ & 200 & 31.5 & 72.9 & 49.4 & 3239 \\
\hline & Netherlands & $113(5.4)$ & 1601 & 7.1 & 72.0 & 49.1 & 5202 \\
\hline & Norway & $90(4.3)$ & 500 & 18.0 & 72.8 & 49.9 & 6347 \\
\hline & Poland & $152(7.3)$ & 422 & 36.0 & 65.8 & 41.5 & 1570 \\
\hline & Portugal & $65(3.1)$ & 227 & 28.6 & 71.0 & 48.2 & 2690 \\
\hline & Romania & 177 (8.5) & \multicolumn{2}{|c|}{ Not known } & \multicolumn{2}{|c|}{ Data not available } & 1079 \\
\hline & Scotland & $65(3.1)$ & 350 & 18.6 & 66.5 & 43.7 & 3377 \\
\hline & Slovenia & $104(5.0)$ & 352 & 29.5 & 69.5 & 44.8 & 2698 \\
\hline & Spain & 446 (21.4) & \multicolumn{2}{|c|}{ Not known } & 70.3 & 46.8 & 2966 \\
\hline & Sweden & 79 (3.8) & 400 & 19.8 & 75.9 & 51.5 & 5219 \\
\hline & Switzerland & $64(3.1)$ & 100 & 64.0 & 75.7 & 50.2 & 6468 \\
\hline & Total & $2086(100)$ & & & & & \\
\hline
\end{tabular}


* Calculated from data provided by B. Silverman, Israel Ministry of Health (personal communication, 7

September 2017) and Y. Schonmann, London School of Hygiene \& Tropical Medicine (personal communication, 7 September 2018).

Table 2. Demographic distributions of respondents. 


\begin{tabular}{|c|c|c|}
\hline & & Number (\%) \\
\hline \multirow[t]{3}{*}{ Gender } & Female & $1274(61.1)$ \\
\hline & Male & 790 (37.9) \\
\hline & Not stated & $22(1.1)$ \\
\hline \multirow[t]{6}{*}{ Years since graduation } & $<10$ years & $331(15.5)$ \\
\hline & 10-19 years & $553(26.9)$ \\
\hline & 20-29 years & $609(29.2)$ \\
\hline & 30-39 years & $499(23.9)$ \\
\hline & 40 years or over & $76(3.6)$ \\
\hline & Not stated & $18(0.9)$ \\
\hline \multirow[t]{5}{*}{ Site of practice } & Urban & $1238(59.3)$ \\
\hline & Rural & $485(23.3)$ \\
\hline & Remote or Island & $56(2.7)$ \\
\hline & Mixed & $295(14.1)$ \\
\hline & Not stated & $12(0.6)$ \\
\hline \multirow[t]{8}{*}{ Number of doctors in practice } & 1 & 286 (13.7) \\
\hline & 2 & $233(11.2)$ \\
\hline & 3 & $226(10.8)$ \\
\hline & $4-5$ & 347 (16.6) \\
\hline & $6-7$ & $259(12.4)$ \\
\hline & $8-9$ & $172(8.2)$ \\
\hline & 10 or more & $542(26.0)$ \\
\hline & Not stated & $21(1.0)$ \\
\hline
\end{tabular}


Table 3. Overall likelihood of immediate diagnostic action by years since graduation.

\begin{tabular}{|c|c|}
\hline Years since graduation & Likelihood of immediate diagnostic action, \% \\
\hline$<10$ years & 55.5 \\
\hline $10-19$ years & 62.8 \\
\hline 20-29 years & 63.1 \\
\hline 30-39 years & 64.5 \\
\hline 40 years or over & 64.1 \\
\hline
\end{tabular}

Table 4. Overall likelihood of immediate diagnostic action by practice size.

\begin{tabular}{|c|c|}
\hline Number of PCPs in respondent's practice & Likelihood of immediate diagnostic action, \% \\
\hline 1 & 72.5 \\
\hline 2 & 67.4 \\
\hline 3 & 62.5 \\
\hline $4-5$ & 62.9 \\
\hline $6-7$ & 58.2 \\
\hline $8-9$ & 57.1 \\
\hline 10 or more & 57.6 \\
\hline
\end{tabular}




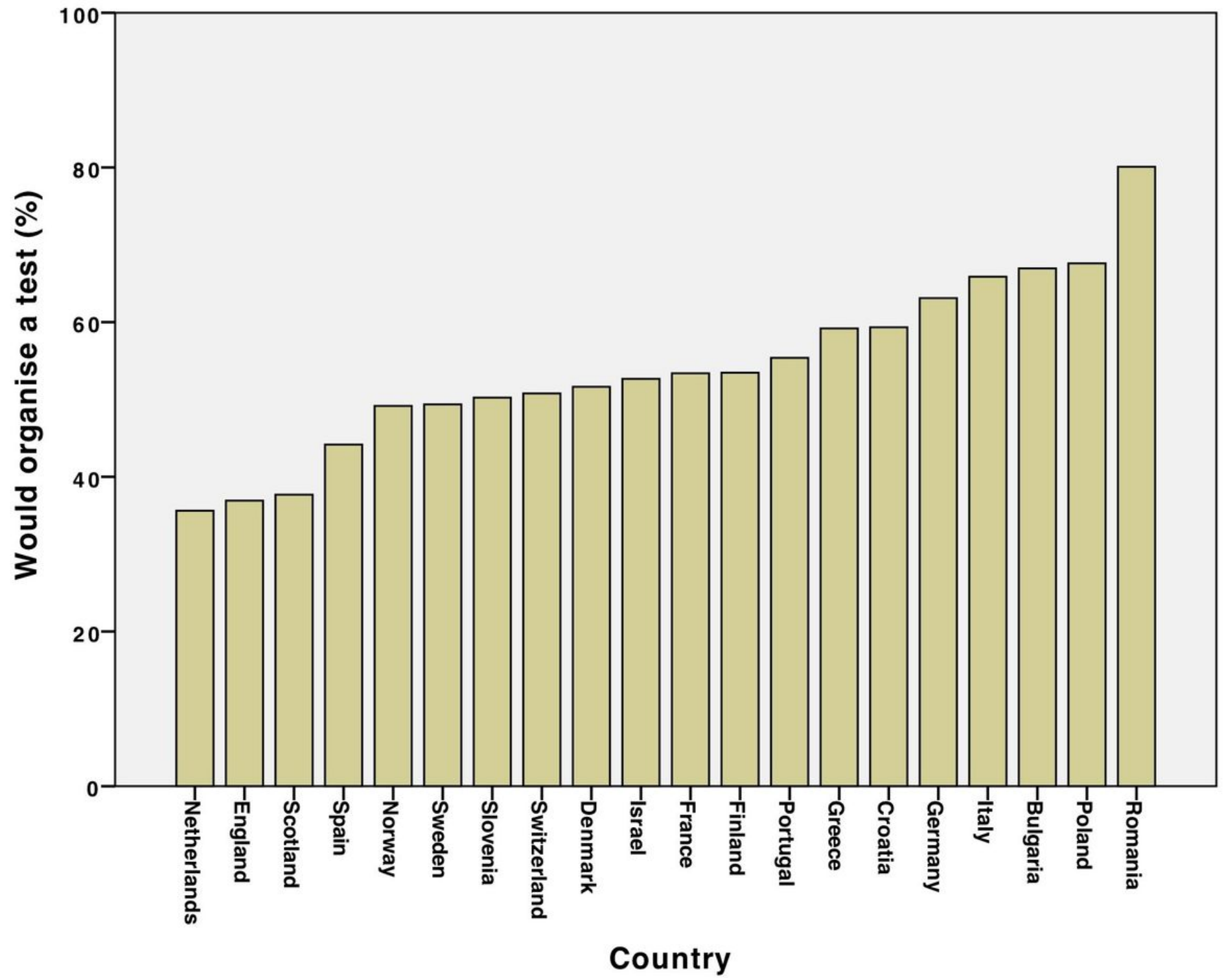

Figure 1

Percentage of PCPs in each country who would organise a diagnostic test. 


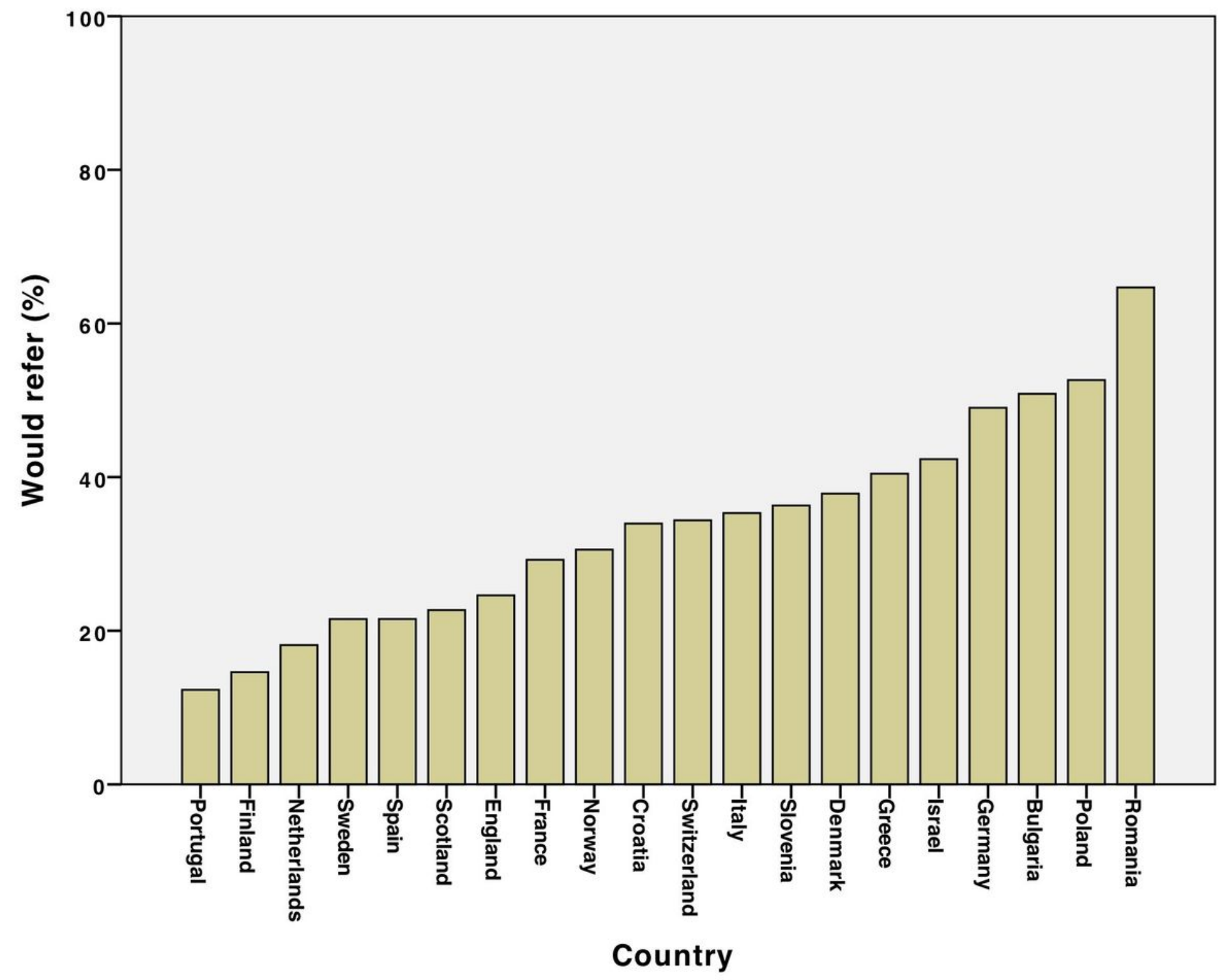

Figure 2

Percentage of PCPs in each country who would refer the patients to a specialist. 


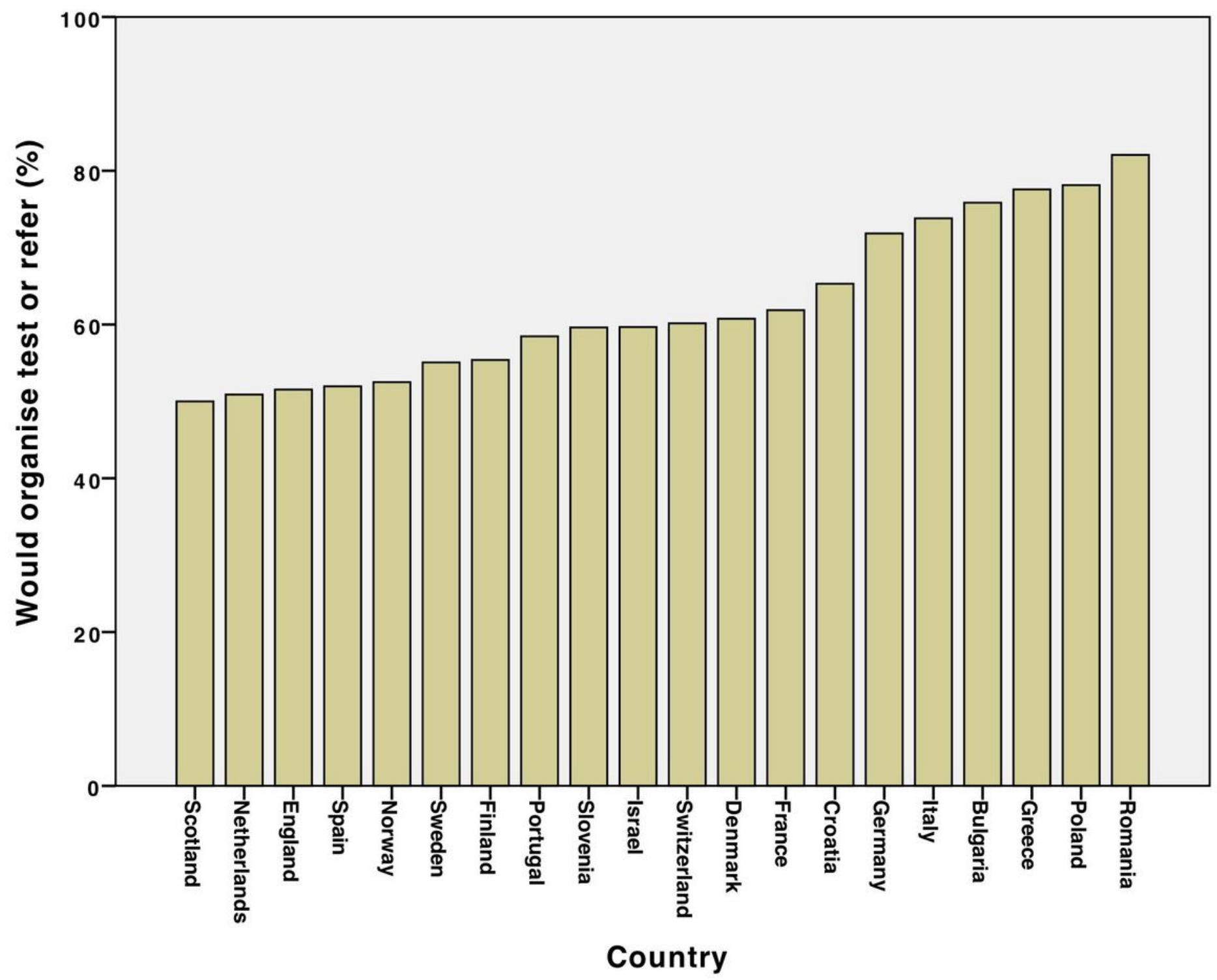

Figure 3

Percentage of PCPs in each country who would organise an investigation and/or refer the patients to a specialist. 


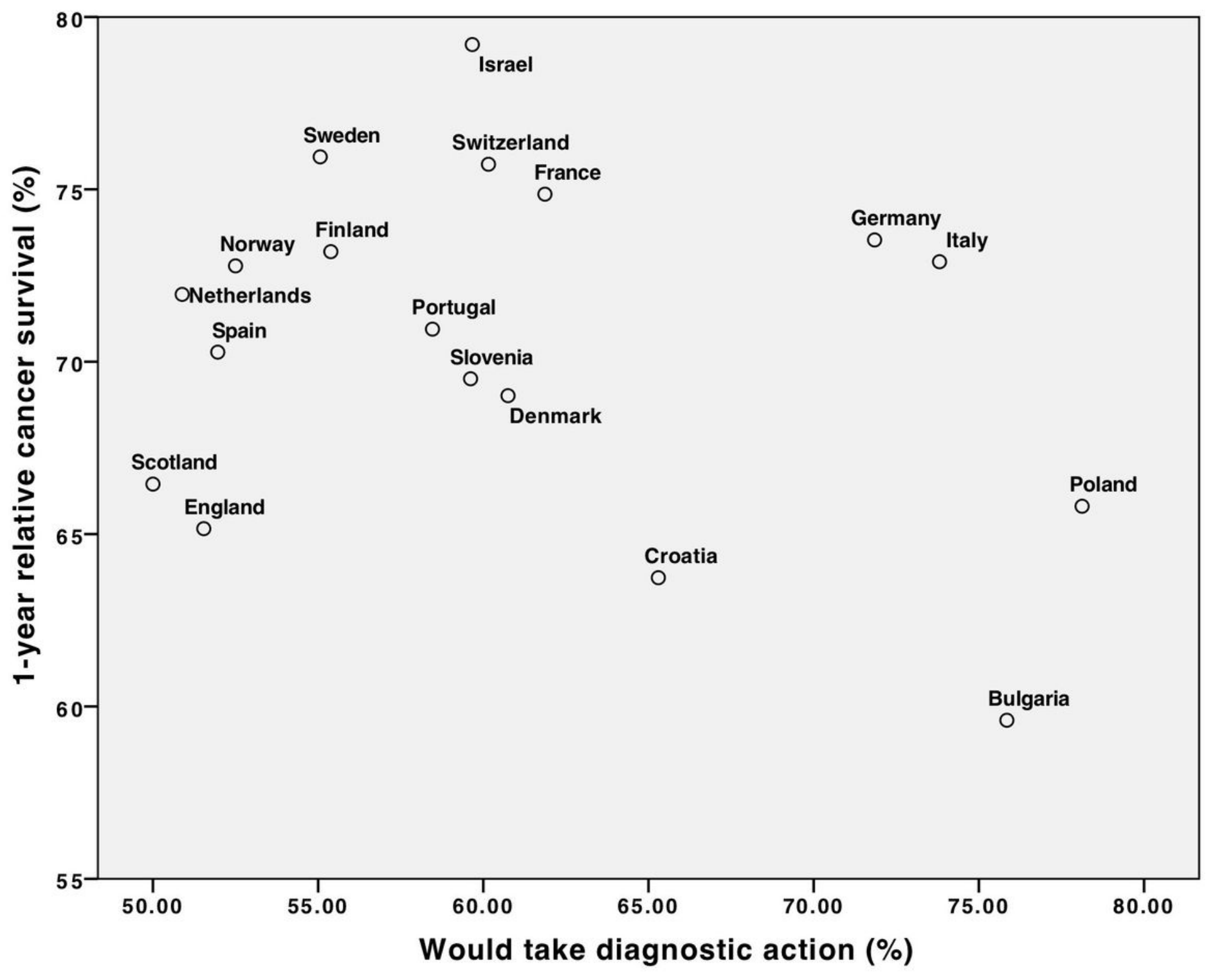

Figure 4

Percentage of PCPs in each country who would organise a diagnostic test. 


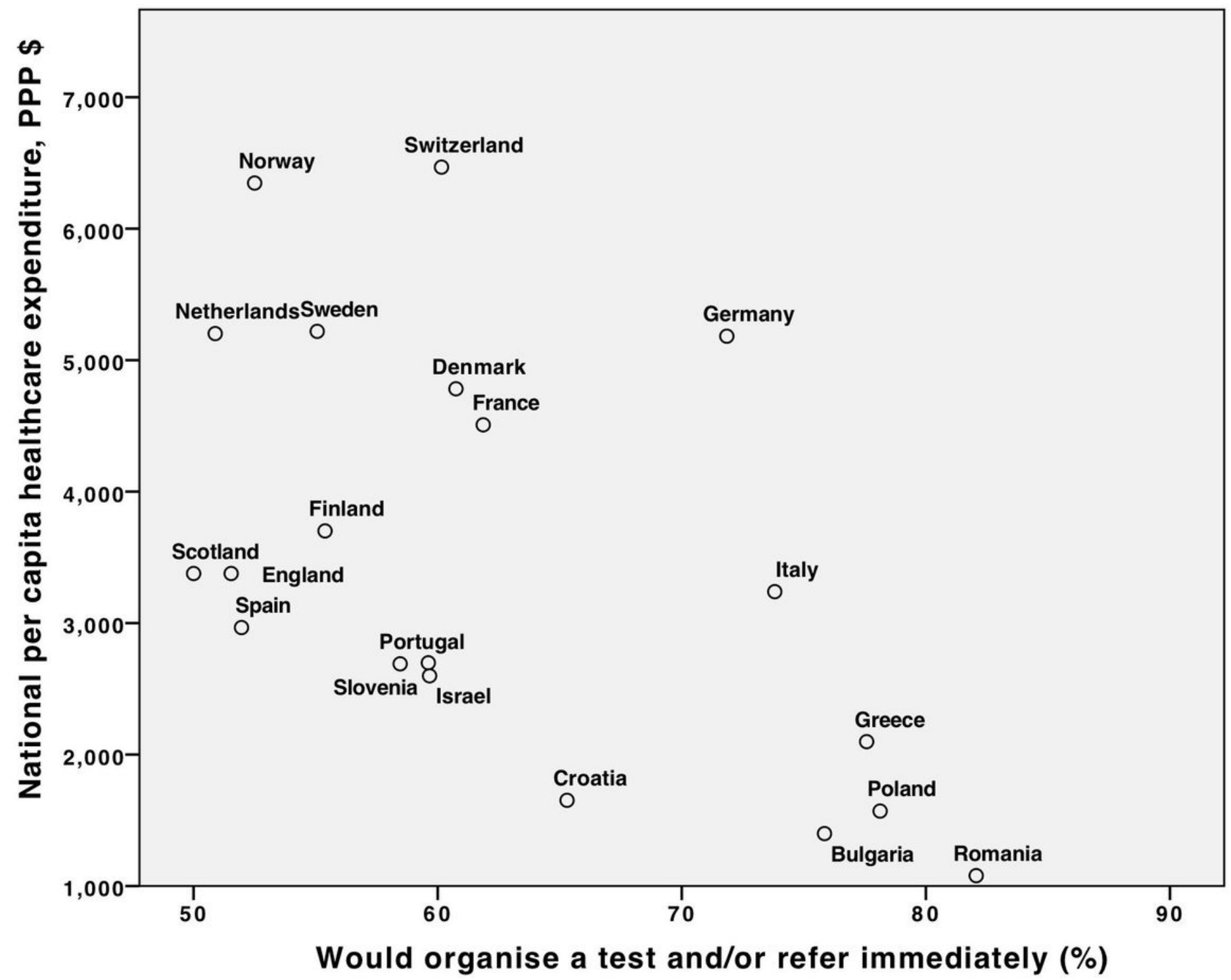

Figure 5

Percentage of PCPs in each country who would refer the patients to a specialist. 